\title{
Clinical presentation of intussusception in Swedish children under 3 years of age and the validity of diagnostic coding
}

\author{
Lina Schollin Ask ${ }^{1,2}$ (D) Jan F. Svensson ${ }^{3,4} \cdot$ Ola Olén ${ }^{1,2} \cdot$ Åke Örtqvist ${ }^{5,6}$
}

Accepted: 21 November 2018 / Published online: 26 November 2018

(c) The Author(s) 2018

\begin{abstract}
Purpose Intussusception has been associated with rotavirus vaccine. The rotavirus vaccine will soon be introduced in the Swedish national immunization program. A validation of the diagnosis of intussusception among Swedish children in the Swedish National Patient Register is needed, as a basis for future vaccine safety surveillance by Swedish registers.

Methods This diagnostic study reviewed the medical admission records of 392 Swedish children with intussusception from 1987 to 2013. The records were randomly selected by The National Board of Health and Welfare from all Sweden and from both pediatric and pediatric surgery care. Positive predictive values (PPV) were calculated to study the concordance between the diagnosis coded in the Swedish Patient Register and the accepted international criteria of case definitions.

Results The PPV for a definitive diagnosis, based on certain radiology findings or surgery, was $84 \%$. When clinically probable cases were added the PPV was $87 \%$. When cases of possible intussusception were added the PPV was $89 \%$. The PPV for the 240 children under 1 year was $88 \%$.

Conclusion Swedish health care registers can be used in the evaluation of incidences of intussusception when rotavirus vaccine will be introduced, due to a high validity of the diagnosis of intussusception in the registers.
\end{abstract}

Keywords Children $\cdot$ Diagnostic coding $\cdot$ Intussusception $\cdot$ Rotavirus vaccine $\cdot$ Validation study

\section{Introduction}

Since 2013, the World Health Organization (WHO) has recommended all countries to vaccinate against the rotavirus infection, which is the most common global cause of severe diarrhea in children under 5 years of age [1]. By the end of

Lina Schollin Ask

lina.schollin-ask@sll.se

1 Sach's Children and Youth Hospital, South General Hospital, Sjukhusbacken 10, 11883 Stockholm, Sweden

2 Department of Medicine, Clinical Epidemiology Unit, Karolinska Institutet, Stockholm, Sweden

3 Department of Paediatric Surgery, Karolinska University Hospital, Stockholm, Sweden

4 Department of Women's and Children's Health, Karolinska Institutet, Stockholm, Sweden

5 Department of Communicable Disease Control and Prevention, Stockholm County Council, Stockholm, Sweden

6 Division of Infectious Diseases, Department of Medicine, Solna, Karolinska Institutet, Stockholm, Sweden
2016, the vaccination had been introduced into 90 countries [2].

In February 2017, the Swedish Government decided to include the rotavirus vaccination in the national child vaccination program. The national inclusion has not started yet but it has already been implemented in some regions, such as Stockholm County.

The rotavirus vaccination has been associated with an increased risk of intussusception [3-10] and the WHO has pointed out the importance of performing national surveys of this diagnosis when a country introduces the vaccine.

Intussusception is a severe condition, where the bowel folds into itself and causes an obstruction that could result in death if not treated [11]. In countries similar to Sweden it occurs most frequently in small children. The peak age is $4-8$ months and the baseline incidence varies between 27 and 101 cases per 100,000 children who are less than 1 year old in high income settings [12]. It is more common in boys $[11,13]$ and the most frequent symptoms are described as the classic triad of vomiting, rectal bleeding or bloody stools, and intermittent abdominal pain, although a wide range of symptoms may appear 
[11]. Intussusception is treated by radiological techniques, using liquid contrast enemas or gas enemas, or by surgery $[14,15]$.

The diagnosis of intussusception has been validated in some countries, but not in Sweden [16, 17]. However, an international clinical case definition has been developed for the diagnosis of intussusception by the Brighton collaboration to standardize and facilitate the safety surveillance of the rotavirus vaccine $[18,19]$.

The primary aim of our study was to use these international criteria to validate the diagnosis of intussusception in the Swedish National Patient Register for children under 3 years of age. This would facilitate a future surveillance of the incidence of intussusception by the register.

\section{Materials and methods}

\section{Study population}

The National Board of Health and Welfare identified a random sample of 500 cases who were under 3 years of age and had received their first diagnostic listing of intussusception in the Swedish National Patient Register between 1987 and 2013. The records were randomly selected from all geographic areas in Sweden and from both pediatric and pediatric surgery departments, since there is a tradition in Sweden of seeking care for young children with abdominal pain in both types of clinics. Intussusception was defined according to the International Classification of Diseases, as 560A in the Ninth Revision and K56.1 in the Tenth Revision. We requested 500 medical records from the different hospitals around Sweden and received $392(78 \%)$.

\section{The Brighton criteria for intussusception}

This study used the international clinical case definition of intussusception to categorize all medical records into the three different levels of diagnostic certainty: level one was definite, level two was probable and level three was possible intussusception [19] (Fig. 1). The criteria for this clinical case definition has a sensitivity of nearly $100 \%$ and specificity of $87-100 \%[19,20]$.

\section{The Swedish National Patient Registry}

Since 1987, the Swedish National Patient Register has achieved a complete coverage of all hospital admissions in Sweden and the validity has been shown to be high (85-95\%) for several different diagnoses [21-23].

\section{Procedure}

One of the authors, who is a pediatrician (LSA), reviewed the medical records according to the international criteria. When there was any doubt concerning any of the information, the medical records were discussed with another author (JFS), who is an experienced pediatric surgeon. They discussed 53 records and agreements were reached in each case.

\section{Statistical analysis}

Based on earlier Swedish and European data [24, 25], we assumed that from 1987 to 2013 there would have been about 6000 cases of intussusception in Sweden in children who were less than 3 years of age. We estimated that records from 330 admissions would be enough to produce a generalizable estimated PPV of $80 \%$ with a $95 \%$ confidence interval (CI) with a precision of $4 \%$ either side of the PPV. From our earlier experiences in the research group, we knew that it was not possible to obtain all of the requested records and that we would probably lose about a third. That is why 500 records were requested.

Positive predictive values (PPVs) were calculated with 95\% confidence intervals using binomial distribution [26] for each level of intussusception and any missing information on the variables was assumed to be negative in all the analyses. SPSS Statistics, version 22.0 (IBM Corp, Armonk, NY, USA), was used for the statistical analyses.

\section{Results}

\section{Demographics of the study population}

Table 1 presents the demographics of the study population. Medical records from the 392 admissions were reviewed and the majority were male, 262/392 (67\%). With regard to age, 240/392 (61\%) were less than 1 year old and 156/392 (40\%) were between 3 and 9 months of age at the time of admission. The median age was 9 months (interquartile range 5-17 months). Figure 2 shows the age distribution of the study population. Admissions data showed that in 44/392 (11\%) cases both a pediatric and a surgical department were involved, in 139/392 (35\%) cases only a surgical department was involved and in 209/392 (53\%) cases only a pediatric department was involved. 


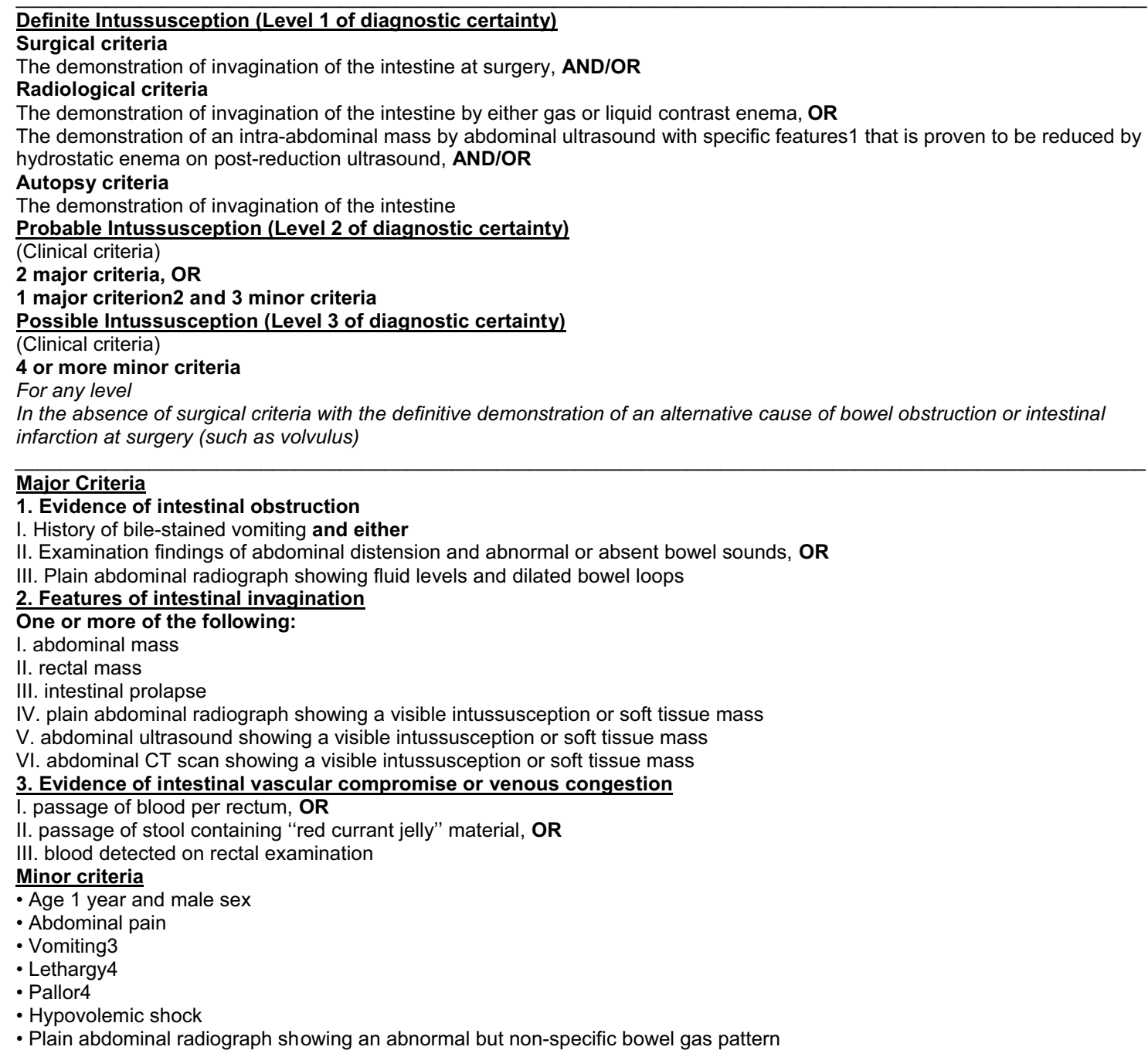

\section{Notes for Case Definition}

1Target sign on doughnut sign on transverse section and a pseudo-kidney or sandwich sign on longitudinal section; 2 lf 1 major criterion is rectalbleeding in the form of blood mixed with diarrhoea then consideration should be given to infectious causes, such as E.coli, shigella or amoebiasis. In such cases 2 major criteria should be met.

Notes for the criteria

3If the vomiting is bile-stained, it cannot be counted twice as a major and minor criterion; 4lethargy and pallor typically occur intermittently in association with acute spasms of abdominal pain. In patients with severe or prolonged intussusception, lethargy and pallor may become a constant feature associated with a deterioration in cardiovascular status and impending hypovolemic shock.

Reproduced with permission from the publishers, Wolters Kluwer, Lippincott Williams \& Wilkins.

Fig. 1 Clinical case definition for the diagnosis of acute intussusception by Bines et al

\section{Positive predictive values}

Figure 3 presents all different levels of PPV. In 348/392 cases, the Brighton collaboration case definitions of intussusception were fulfilled for at least one of the three levels of diagnostic certainty for intussusception (PPV 89\%, 95\% CI 86-92). When we reviewed the whole cohort, the criteria for definite intussusception (level one) were met by $330 / 392$ children (PPV 84\%, 95\% CI 82-86) and by 12/392 (3\%) for probable intussusception (level two) and 6/392 (2\%) for possible intussusception (level three). When the PPV for levels one and two were combined, it was 87\% (95\% CI 84-90). In the subgroup of the 240 children who were less than 1 year old, the PPV for at least one of the three levels of diagnostic certainty for intussusception was 212/240 (88\%) (95\% CI 84-92). 
Table 1 Demographics of the 392 children with a diagnosis of intussusception

\begin{tabular}{ll}
\hline Variables & $N(\%)$ \\
\hline Gender & $262(67)$ \\
Boy & $130(33)$ \\
Girl & \\
Age & $28(7)$ \\
0-2 months & $75(19)$ \\
3-5 months & $81(21)$ \\
6-8 months & $56(14)$ \\
$9-11$ months & $87(22)$ \\
12-23 months & $65(17)$ \\
$24-35$ months & \\
Time period & $196(50)$ \\
1987-1996 (ICD-9 code 560A) & $196(50)$ \\
1997-2013 (ICD-10 code K56.1) & \\
Type of department & $139(35)$ \\
Surgical & $209(53)$ \\
Pediatric & $44(11)$ \\
Both & 392 \\
Total &
\end{tabular}

\section{Clinical symptoms}

All the symptoms and findings from radiology and surgery that appeared in the 392 cases are presented in Table 2. The most frequent symptom, in $346 / 392$ (88\%) of the cases, was a history or signs of abdominal pain and this was irrespective of the level of diagnostic certainty. Passing blood from the rectum was reported in 147/392 (38\%) patients and some of those also had stools containing what was described as "red currant jelly" and/or blood detected during rectal examinations. Only 92/392 (23\%) of the total cohort presented with all three symptoms of the classic triad, namely vomiting, abdominal pain and rectal bleeding or bloody stools.

\section{Findings of radiology and surgery}

Table 3 shows the results and findings of radiology and surgery in the study population. We found that 370 (94\%) of the 392 children underwent a procedure with gas or liquid contrast enemas and $318 / 370(86 \%)$ of these procedures were positive for a visible intussusception. It was possible to reduce the intussusception in 285/370 (77\%) children when an enema was used. Ultrasound was performed on 107/392 (27\%) children and 97/107 (91\%) of these demonstrated visible intussusception or soft tissue mass. Ultrasound was performed less commonly during 1987-1999, (26/240, 11\%) than during 2000-2013 (81/152, 53\%) and in the last 2 years of the study, from 2012 to 2013, it was even higher (24/34, $71 \%)$. A visible soft tissue mass or intussusception was shown in $231 / 339$ (68\%) children who underwent a plain abdominal radiograph and 182/339 children (54\%) had signs of abnormal but non-specific bowel gas patterns. Only 3/392 children (1\%) had performed abdominal computed tomography and all of them had a visible intussusception.

The radiological criteria for intussusception were fulfilled by $319 / 392$ children ( $81 \%$ ) children and in $318 / 319$ cases it was carried out by gas or liquid contrast enema. In 73/318 (23\%) of these children, it was not possible to reduce the intussusception and surgery was required. Ultrasound was used for the other case that fulfilled the criteria.

We found that $84 / 392$ children (21\%) fulfilled the surgical criteria. In $11(13 \%)$ of these 84 cases, the child was in such a poor condition that surgery was performed without examining them with a gas or liquid contrast enema and 36/84 (43\%) had signs of fluid levels and dilated bowel loops when a plain abdominal radiograph was performed. There were no deaths in the whole cohort of 392 children.
Fig. 2 Age distribution for the study population of 392 children under 3 years of age with a diagnosis of invagination (ICD-9 560A or ICD-10 K56.1) in Sweden, 1986-2013

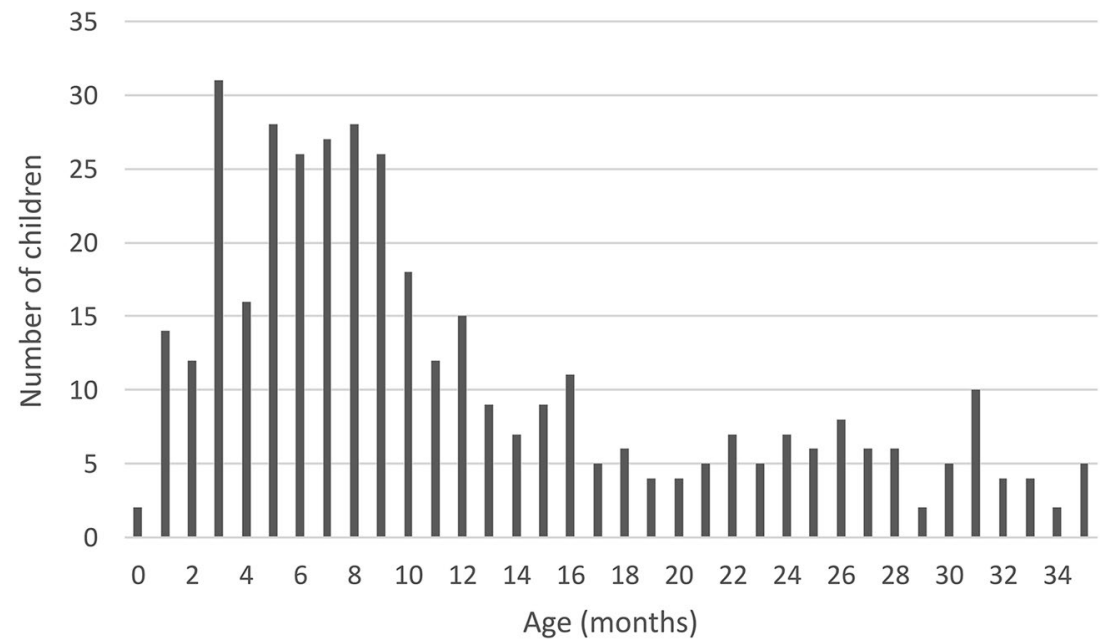


Fig. 3 Procedure and main results

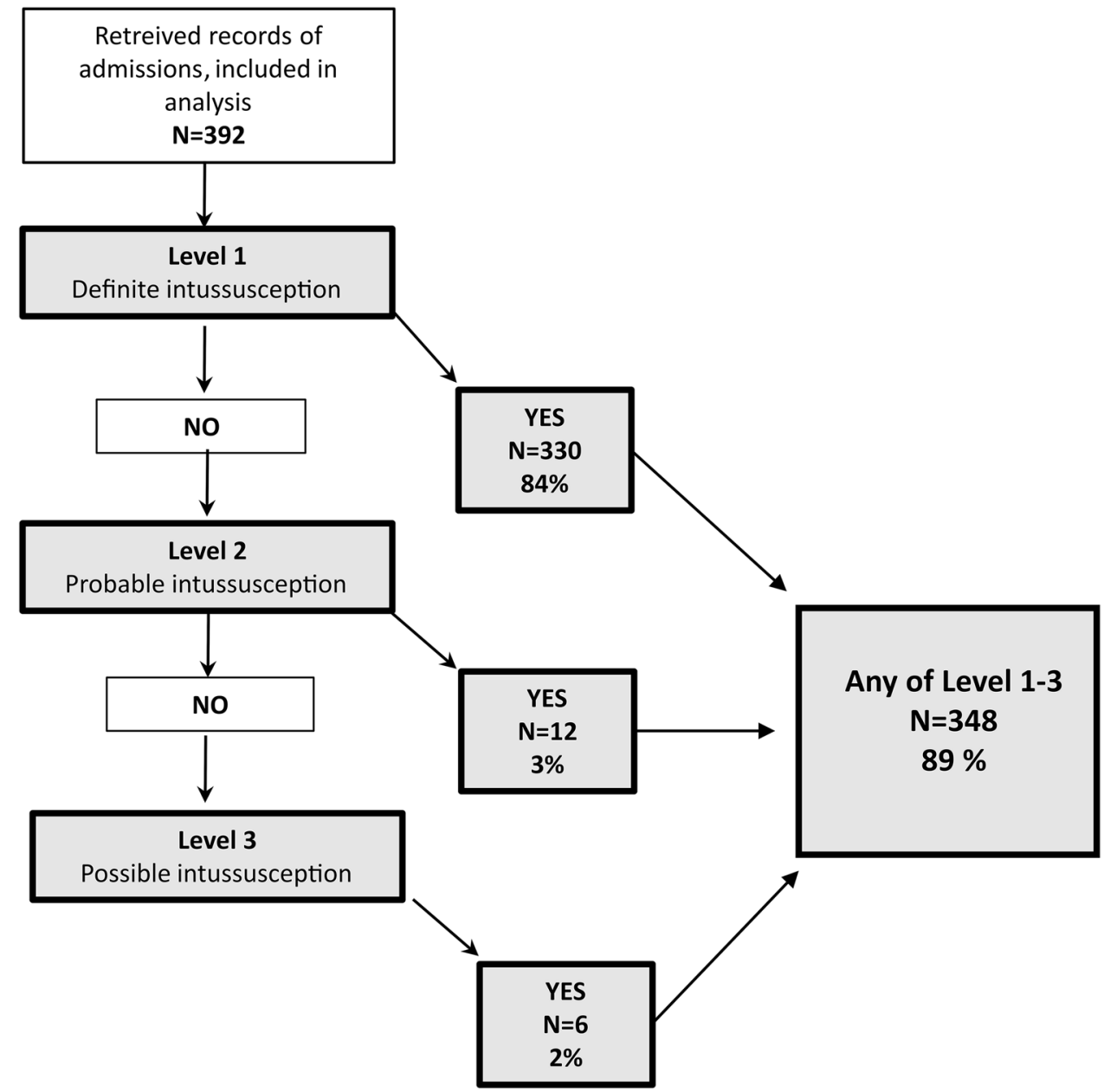

\section{Discussion}

\section{Main findings}

This nationwide Swedish study examined the validity of the coding for intussusception for children who were younger than 3 years old in the Swedish National Patient Register and found that it was high in 392 cases between 1987 and 2013. The PPV was $84 \%$ (95\% CI 82-86) when typical radiological findings or surgery were required for a diagnosis of intussusception and up to $89 \%$ when clinically likely cases were also included. For the subgroup of children below 1 year of age the PPV was $88 \%$.

\section{Comparisons with earlier studies}

Our findings were in accordance with those from other countries presenting PPVs that fulfilled at least one of the three levels of diagnostic certainty for intussusception, which were $73 \%$ in Canada [17], 81-86\% in Great Britain [27] and $86 \%$ in Switzerland [28]. Therefore, our results could be used as a platform for further studies of vaccine safety after the national introduction of the rotavirus vaccine in Sweden.

\section{Clinical symptoms}

We demonstrated that children that were affected by intussusception presented with a wide range of symptoms, which emphasizes the importance of describing them as carefully as possible in medical records to facilitate later evaluation of the diagnoses. European studies have reported that the classic triad of symptoms, of vomiting, abdominal pain and rectal bleeding or bloody stools, were present in $10-66 \%$ of cases $[11,25]$. In our study, the triad was present in $24 \%$ of the cases, while the most frequent symptom (88\%) was abdominal pain, which was consistent with other studies [16, 20]. Abdominal pain has been shown to have a high PPV of $99 \%$, a high negative predictive value of $100 \%$ and a high sensitivity $90 \%$, but a specificity of just $19 \%$ when validated within the Brighton criteria for intussusception [20]. 
Table 2 Symptoms, and radiology and surgical findings according to the Brighton Collaboration Case definitions in 392 admissions diagnosed with acute intussusception in Sweden during 1987-2013

\begin{tabular}{|c|c|c|c|}
\hline Variables & $\begin{array}{l}\text { Level } 1 \text { definite intussuscep- } \\
\text { tion }(N=330) \\
N(\% \text { of level } 1)\end{array}$ & $\begin{array}{l}\text { Children }<1 \text { year all levels } \\
(N=240) \\
N(\% \text { of all }<1 \text { year })\end{array}$ & $\begin{array}{l}\text { Total all levels } \\
(N=392) \\
N(\% \text { of all })\end{array}$ \\
\hline \multicolumn{4}{|l|}{ Minor criteria } \\
\hline Age $<1$ year and male sex & $128(39)$ & $155(65)$ & $159(41)$ \\
\hline Abdominal pain & $296(90)$ & $204(85)$ & $346(88)$ \\
\hline Vomiting & $236(72)$ & $176(73)$ & $257(66)$ \\
\hline Lethargy & $179(54)$ & $126(53)$ & $194(49)$ \\
\hline Pallor & $129(39)$ & $97(40)$ & $145(37)$ \\
\hline Hypovolemic shock & $11(3)$ & $8(1)$ & $11(3)$ \\
\hline $\begin{array}{l}\text { Plain abdominal radiograph showing an abnormal but non- } \\
\text { specific bowel gas pattern }\end{array}$ & $161(49)$ & $116(48)$ & $182(46)$ \\
\hline \multicolumn{4}{|l|}{ Major criteria } \\
\hline History of bile-stained vomiting & $23(7)$ & $22(9)$ & $23(6)$ \\
\hline $\begin{array}{l}\text { Abdominal distension and abnormal or absent bowel sounds } \\
\text { on examination }\end{array}$ & $61(18)$ & $42(18)$ & $67(17)$ \\
\hline $\begin{array}{l}\text { Plain abdominal radiograph showed fluid levels and dilated } \\
\text { bowel loops }\end{array}$ & $69(21)$ & $50(21)$ & $71(18)$ \\
\hline Abdominal mass & $73(22)$ & $52(22)$ & $77(20)$ \\
\hline Rectal mass & $2(1)$ & $1(1)$ & $2(1)$ \\
\hline Intestinal prolapse & $2(1)$ & $2(1)$ & $2(1)$ \\
\hline $\begin{array}{l}\text { Plain abdominal radiograph showed a visible intussusception } \\
\text { or soft tissue mass }\end{array}$ & $228(69)$ & $141(59)$ & $231(59)$ \\
\hline $\begin{array}{l}\text { Abdominal ultrasound showed a visible intussusception or } \\
\text { soft tissue mass }\end{array}$ & $95(29)$ & $53(22)$ & $97(25)$ \\
\hline $\begin{array}{l}\text { Abdominal CT scan showed a visible intussusception or soft } \\
\text { tissue mass }\end{array}$ & $2(1)$ & $1(1)$ & $3(1)$ \\
\hline Passing blood from rectum & $127(38)$ & $120(50)$ & $147(38)$ \\
\hline Passing stools resembling "red currant jelly" & $30(9)$ & $32(13)$ & $37(10)$ \\
\hline Blood detected during rectal examination & $29(9)$ & $27(11)$ & $32(8)$ \\
\hline \multicolumn{4}{|l|}{ Criteria related to level 1} \\
\hline Surgical criteria* & $84(21)$ & $62(26)$ & $84(21)$ \\
\hline Radiological criteria** & $319(97)$ & $191(80)$ & $319(81)$ \\
\hline Autopsy criteria*** & 0 & 0 & 0 \\
\hline
\end{tabular}

\section{CT computerized tomography}

*The demonstration of invagination of the intestine at surgery

**The demonstration of invagination of the intestine by either gas or liquid contrast enema, OR

The demonstration of an intra-abdominal mass by abdominal ultrasound with specific features 1 that is proven to be reduced by hydrostatic enema on post-reduction ultrasound

$* * *$ The demonstration of invagination of the intestine by autopsy

Table 3 Number of cases where radiology was performed, based on the total study cohort of 392 children

\begin{tabular}{llll}
\hline Radiology performed, $n / 392(\%)$ & $\begin{array}{l}\text { Abnormal but non-specific } \\
\text { bowel gas pattern } \\
N(\%)\end{array}$ & $\begin{array}{l}\text { Visible intussusception or } \\
\text { soft tissue mass } \\
N(\%)\end{array}$ & $\begin{array}{l}\text { Fluid levels and } \\
\text { dilated bowel loops } \\
N(\%)\end{array}$ \\
\hline Plain abdominal radiograph, 339 performed (86\%) & $182 / 339(54)$ & $231 / 339(68)$ & $71 / 339(21)$ \\
Abdominal ultrasound 107, performed (27\%) & - & $97 / 107(91)$ & - \\
Abdominal CT scan, 3 performed (1\%) & - & $3 / 3(100)$ & - \\
Gas or liquid contrast enema, 370 performed (94\%) & - & $318 / 370(86)$ & - \\
\hline
\end{tabular}




\section{Radiology}

The Brighton collaboration criteria for intussusception, together with our results, emphasize the importance of using gas or liquid contrast enemas or abdominal ultrasound to verify the diagnosis, if the child is in a clinically stable condition. Most of the children in our study (94\%) were examined by gas or liquid contrast enemas and $86 \%$ of these were positive for intussusception, compared to $65 \%$ who showed visible signs of intussusception when plain abdominal radiographs were performed.

Earlier Swedish studies showed that the success rate of enema therapy was more than $70 \%[29,30]$, which was consistent with the $77 \%$ found in our study. Ultrasound examinations were only performed in $27 \%$ of cases, but of these cases $91 \%$ were positive for intussusception, indicating that this relatively harmless diagnostic method may have been underused. When we compared the oldest and most recent time periods during the 1987-2013 study, we found that a higher proportion of children underwent ultrasound during the later periods. The sensitivity of abdominal ultrasound in children affected by intussusception has been shown to be nearly $100 \%$, while specificity has been reported to range from 78 to $100 \%$ [31, 32]. However, the performance of an abdominal ultrasonography depends on the operator and the quality of the performance can vary between hospitals and even during 1 day in the same hospital [15,33].

\section{Surgery}

In total, $21 \%$ of our children had findings of intussusception during surgery, which was similar to the $14 \%$ found in a European study [25] and the $28 \%$ in a study from the United States [12].

The treatment for intussusception is predominantly surgical in developing countries. The reason for this is that families often have to travel much greater distances to hospitals and children have a longer duration of symptoms and develop more severe conditions before a diagnosis of intussusception can be made [34].

\section{Strengths and limitations}

One of the strengths of this study was the population-based design and the fact that it was based on a random sample from a nationwide patient register. Another strength was the use of standardized case definitions from the Brighton collaboration, which has been described as a reliable method when compared to non-systematic reviews [35-37].

However, there were some limitations to this study, including the retrospective study design, which meant that all of the available information depended on the quality of the reported information in the medical records. If information was missing on a variable in the case notes, it was analyzed as negative rather than being excluded. A previous study reported that using this procedure can dilute the results and lead to the PPV being lower than it should be [16]. Another limitation was that we depended on the reviewer's interpretation of the symptoms and findings. In a previous study, different clinicians only agreed on the level of intussusception in $49 \%$ of cases, but there were no disagreements with regard to positive and negative diagnoses [20]. When the primary reviewing author in our study had any doubts about any information relating to a case, the medical record was discussed with a second reviewer until a consensus was reached. Furthermore, the radiology results were only available as written information, no radiological evaluation was performed and we did not have access to radiology procedure codings, which could have increased the PPV. However, in a similar validation study in Ontario in 2013 [17], PPV increased from 72.4 to $81.7 \%$ while sensitivity decreased from 89.3 to $71.2 \%$ when a procedure code for a diagnostic enema or enema reduction was added to the International Classification of Diseases codes. These were validated by the same case definitions used in our study. Finally, we assumed that all children with intussusception were taken care of in hospitals and a limitation was that it was difficult to capture children with spontaneously reduced intussusception [28]. In such cases, initial symptoms may resolve spontaneously after admission and all the results of the examinations will be negative [28]. Although such children should have been captured by the level two or three case definitions in our study, they might as well be validated as not being a case of intussusception [38]. A future challenge is to study the use of case definitions in cases of intussusception as an adverse effect of the rotavirus vaccine. Because the children affected by intussusception as an adverse event of rotavirus will be younger than the age when the incidence of intussusception naturally peaks, they will might show a different clinical picture because of their young age [38].

\section{Conclusions}

The validity of the coding for intussusception in the Swedish National Patient Register among children who were younger than 3 years was high, at $89 \%$. Our findings suggest that when the rotavirus vaccine is introduced to the national child vaccination program in Sweden, its safety can be monitored using the Swedish National Patient Register and coding the diagnosis as intussusception.

Acknowledgements This work was supported by the Samariten Foundation, Stockholm County Council; the Department of Communicable 
Disease Control and Prevention; the Crown Princess Lovisa Foundation and Sällskapet Barnavård.

\section{Compliance with ethical standards}

Conflict of interest The authors declare that they have no conflict of interest.

Ethical approval Ethical approval was obtained from the Stockholm Regional Ethics Committee (2014/2121-31/4).

Informed consent For this type of study informed consent is not required.

Open Access This article is distributed under the terms of the Creative Commons Attribution 4.0 International License (http://creativeco mmons.org/licenses/by/4.0/), which permits unrestricted use, distribution, and reproduction in any medium, provided you give appropriate credit to the original author(s) and the source, provide a link to the Creative Commons license, and indicate if changes were made.

\section{References}

1. WHO (2013) Weekly epidemiological record, Rotavirus position paper 5(8):49-64.http://www.who.int/wer/2013/wer88 05.pdf?ua=1. Accessed $1 \mathrm{Feb} 2013$

2. Data GHOG (2018) Rotavirus (RotaC) immunization coverage. http://www.who.int/gho/immunization/rotavirus/en/

3. http://www.fass.se/LIF/product?userType $=0 \&$ nplId $=2005050500$ 0047. Accessed May 2018

4. http://www.fass.se/LIF/product?userType $=0 \&$ nplId $=2016091300$ 0079. Accessed July 2018

5. Patel MM, Lopez-Collada VR, Bulhoes MM, De Oliveira LH, Bautista Marquez A, Flannery B et al (2011) Intussusception risk and health benefits of rotavirus vaccination in Mexico and Brazil. N Engl J Med 364(24):2283-2292

6. Haber P, Patel M, Pan Y, Baggs J, Haber M, Museru O et al (2013) Intussusception after rotavirus vaccines reported to US VAERS, 2006-2012. Pediatrics 131(6):1042-1049

7. Yih WK, Lieu TA, Kulldorff M, Martin D, McMahill-Walraven $\mathrm{CN}$, Platt R et al (2014) Intussusception risk after rotavirus vaccination in US infants. N Engl J Med 370(6):503-512

8. Velazquez FR, Colindres RE, Grajales C, Hernandez MT, Mercadillo MG, Torres FJ et al (2012) Postmarketing surveillance of intussusception following mass introduction of the attenuated human rotavirus vaccine in Mexico. Pediatr Infect Dis J 31(7):736-744

9. Leino T, Ollgren J, Stromberg N, Elonsalo U (2016) Evaluation of the intussusception risk after pentavalent rotavirus vaccination in finnish infants. PloS One 11(3):e0144812

10. Buttery JP, Danchin MH, Lee KJ, Carlin JB, McIntyre PB, Elliott EJ et al (2011) Intussusception following rotavirus vaccine administration: post-marketing surveillance in the National Immunization Program in Australia. Vaccine 29(16):3061-3066

11. WHO (2002) Acute intussuception in infants and children. Incidence,clinical presentation and management: a global perspective. http://apps.who.int/iris/bitstream/handle/10665/67720/ WHO_V-B_02.19_eng.pdf?sequence=1\&isAllowed=y. Accessed Oct 2002

12. Jiang J, Jiang B, Parashar U, Nguyen T, Bines J, Patel MM (2013) Childhood intussusception: a literature review. PloS One $8(7): \mathrm{e} 68482$
13. Kuppermann N, O’Dea T, Pinckney L, Hoecker C (2000) Predictors of intussusception in young children. Arch Pediatr Adolesc Med 154(3):250-255

14. Stringer MD, Pablot SM, Brereton RJ (1992) Paediatric intussusception. Br J Surg 79(9):867-876

15. Daneman A, Alton DJ (1996) Intussusception. Issues and controversies related to diagnosis and reduction. Radiol Clin North Am 34(4):743-756

16. Bines JE, Liem NT, Justice F, Son TN, Carlin JB, de Campo M et al (2006) Validation of clinical case definition of acute intussusception in infants in Viet Nam and Australia. Bull World Health Organ 84(7):569-575

17. Ducharme R, Benchimol EI, Deeks SL, Hawken S, Fergusson DA, Wilson K (2013) Validation of diagnostic codes for intussusception and quantification of childhood intussusception incidence in Ontario, Canada: a population-based study. J Pediatr 163(4):1073-9.e3

18. Bonhoeffer J, Kohl K, Chen R, Duclos P, Heijbel H, Heininger U et al (2002) The Brighton Collaboration: addressing the need for standardized case definitions of adverse events following immunization (AEFI). Vaccine 21(3-4):298-302

19. Bines JE, Ivanoff B, Justice F, Mulholland K (2004) Clinical case definition for the diagnosis of acute intussusception. J Pediatr Gastroenterol Nutr 39(5):511-518

20. Kohl KS, Magnus M, Ball R, Halsey N, Shadomy S, Farley TA (2008) Applicability, reliability, sensitivity, and specificity of six Brighton Collaboration standardized case definitions for adverse events following immunization. Vaccine 26(50):6349-6360

21. Rosen M (2002) National health data registers: a nordic heritage to public health. Scand J Public Health 30(2):81-85

22. Ludvigsson JF, Andersson E, Ekbom A, Feychting M, Kim JL, Reuterwall C et al (2011) External review and validation of the Swedish national inpatient register. BMC Public Health 11:450

23. Jakobsson GL, Sternegard E, Olen O, Myrelid P, Ljung R, Strid H et al (2017) Validating inflammatory bowel disease (IBD) in the Swedish National Patient Register and the Swedish Quality Register for IBD (SWIBREG). Scand J Gastroenterol 52(2):216-221

24. Sweden PHAo (2014). https://www.folkhalsomyndigheten.se/ globalassets/statistik-uppfoljning/vaccinationsstatistik/bvc/vacci nationsstatistik-barnhalsovarden-2014-riket.pdf. Accessed 2014

25. Huppertz HI, Soriano-Gabarro M, Grimprel E, Franco E, Mezner $Z$, Desselberger U et al (2006) Intussusception among young children in Europe. Pediatr Infect Dis J 25(1 Suppl):S22-S29

26. Fagerland MW, Lydersen S, Laake P (2014) Recommended tests and confidence intervals for paired binomial proportions. Stat Med 33(16):2850-2875

27. Samad L, Cortina-Borja M, Sutcliffe AG, Marven S, Cameron JC, El Bashir $\mathrm{H}$ et al (2016) National hospital data for intussusception: data linkage and retrospective analysis to assess quality and use in vaccine safety surveillance. Vaccine 34(3):373-379

28. Tapiainen T, Bar G, Bonhoeffer J, Heininger U (2006) Evaluation of the Brighton collaboration case definition of acute intussusception during active surveillance. Vaccine 24(9):1483-1487

29. Carstensen H, Ryden CI, Nettelblad SC, Theander G (1984) Lavage as an effective and careful method of treating children. Lakartidningen 81(34):2941-2944

30. Gierup J, Jorulf H, Livaditis A (1972) Management of intussusception in infants and children: a survey based on 288 consecutive cases. Pediatrics 50(4):535-546

31. Bhisitkul DM, Listernick R, Shkolnik A, Donaldson JS, Henricks BD, Feinstein KA et al (1992) Clinical application of ultrasonography in the diagnosis of intussusception. J Ped 121(2):182-186

32. Harrington L, Connolly B, Hu X, Wesson DE, Babyn P, Schuh S (1998) Ultrasonographic and clinical predictors of intussusception. J Ped 132(5):836-839 
33. Bisset GS, Kirks DR (1988) Intussusception in infants and children: diagnosis and therapy. Radiology 168(1):141-145

34. Meier DE, Coln CD, Rescorla FJ, OlaOlorun A, Tarpley JL (1996) Intussusception in children: international perspective. World J Surg 20(8):1035-1039; (discussion 40)

35. Murphy TV, Gargiullo PM, Massoudi MS, Nelson DB, Jumaan AO, Okoro CA et al (2001) Intussusception among infants given an oral rotavirus vaccine. N Engl J Med 344(8):564-572
36. Kramarz P, France EK, Destefano F, Black SB, Shinefield H, Ward JI et al (2001) Population-based study of rotavirus vaccination and intussusception. Pediatr Infect Dis J 20(4):410-416

37. Zanardi LR, Haber P, Mootrey GT, Niu MT, Wharton M (2001) Intussusception among recipients of rotavirus vaccine: reports to the vaccine adverse event reporting system. Pediatrics 107(6):E97

38. Newman J, Schuh S (1987) Intussusception in babies under 4 months of age. CMAJ 136(3):266-269 